\title{
To Determine Dose Response Curves of Dyed Polyvinyl Alcohol Films Irradiated with Gamma-Rays
}

\author{
Vo Thi Anh, Tran Dai Nghiep, Trinh Van Giap \\ Institute for Nuclear Science and Technology, Hanoi, Vietnam \\ Email:vothianhanh@yahoo.com
}

How to cite this paper: Anh, V.T., Nghiep, T.D. and Giap, T.V. (2018) To Determine Dose Response Curves of Dyed Polyvinyl Alcohol Films Irradiated with Gamma-Rays. Open Journal of Safety Science and Technology, 8, 13-19.

https://doi.org/10.4236/ojsst.2018.81002

Received: February 12, 2018

Accepted: March 17, 2018

Published: March 20, 2018

Copyright $\odot 2018$ by authors and Scientific Research Publishing Inc. This work is licensed under the Creative Commons Attribution International License (CC BY 4.0).

http://creativecommons.org/licenses/by/4.0/

\begin{abstract}
The Polyvinyl Alcohol (PVA) films dyed with different colors such as methylene blue (MB), methyl orange (MO), methyl red (MR) and crystal violet (CV) were investigated. The dyed PVA films were irradiated by with $\mathrm{Co}^{60} \gamma$-source in dose range of $1-150 \mathrm{kGy}$. The optical density change in these films at pre and post irradiation was studied by spectrophotometer. The gamma dose response curves of the dyed PVA films were described by saturated exponential function of the energy transfer model with high correlative coefficient. The color sensitivities on the dyed PVA films irradiated by source were different. The PVA films dyed with MB had the highest sensitivity.
\end{abstract}

\section{Keywords}

Dyed Thin Film, Dose Response Curves, Optical Density, Methylene Blue, Methyl Orange, Methyl Red and Crystal Violet

\section{Introduction}

PVA is an excellent matrix for radiochromic centres and widely used for lowand high-dose dosimetry purposes. For example, the colored polyvinyl alcohol films can be used in dosimetry for gamma rays and neutrons in nuclear reactors [1]. Using dosimeters for high doses control of radiation processing is extremely important in the field of radiation technology. The PVA is a tissue-equivalent organic material that occupies a very small place in space. So the PVA material is highly suitable to use in gamma dose measurements [2] [3] [4] [5] [6]. Some researchers in the world have used different colors which have radiation sensitive properties to add to the PVA films for high dose control. The dyed PVA film containing a mixing of ethyl violet and bromophenol blue [7], and the dyed PVA 
film containing methyl red [8] are useful as routine high-dose dosimeter with $\mathrm{Co}^{60} \gamma$-source in the 1 - $30 \mathrm{kGy}$ range. The film dosimeters made from PVA films dyed with methylene blue [9] and methyl orange [10] were studied for high-dose control with $\mathrm{Cs}^{137} \gamma$-source in dose range of $100-200 \mathrm{kGy}$.

Most of these studies have carefully surveyed the factors that affect the discoloration of films such as $\mathrm{pH}$, color concentration, film thickness, pre-irradiation and post-irradiation stabilities. Apart from that, the researchers usually pay attention to investigate discoloration of post-irradiation films for different dose ranges [7] [8] [9] [10]. However, they did not clearly define the dose response curves for the different dose ranges that they surveyed.

The current works are to define the dose response curves of the dyed PVA films. Several dyed PVA films containing difference colors such as crystal violet, methyl red, methylence blue and methyl orange were strongly changing the original colors under $\mathrm{Co}^{60} \gamma$-source and became stable radiochromic thin films which can be used as dosimeter for measurement of radiation doses in different dose ranges.

\section{Materials and Methods}

We prepared four types of film with four different colors. They were the CV-PVA dyed films containing $1 \mathrm{~mL}$ crystal violet $2 \times 10^{-3} \mathrm{M}\left(\mathrm{C}_{25} \mathrm{H}_{30} \mathrm{CIN}_{3}\right.$, Mw = 407.98), the MR-PVA dyed films containing $1 \mathrm{~mL}$ methyl red $0.4 \times 10^{-3} \mathrm{M}$ $\left(\mathrm{C}_{15} \mathrm{H}_{15} \mathrm{~N}_{3} \mathrm{O}_{2}, \mathrm{Mw}=269\right)$, the MB-PVA dyed films containing $5 \mathrm{~mL}$ methylene blue $10^{-3} \mathrm{M}\left(\mathrm{C}_{16} \mathrm{H}_{18} \mathrm{ClN}_{3} \mathrm{~S}_{\mathrm{x}} \times \mathrm{H}_{2} \mathrm{O}, \mathrm{Mw}=391.86\right)$ and the MO-PVA dyed films containing $0.2 \mathrm{~mL}$ methyl orange $10^{-3} \mathrm{M}\left(\mathrm{C}_{14} \mathrm{H}_{14} \mathrm{~N}_{3} \mathrm{NaO}_{3} \mathrm{~S}, \mathrm{Mw}=327.34\right)$. PVA from SIGMA Mw = 89,000 - 98,000 $\mathrm{g} / \mathrm{mol}$, 99\% hydrolyzed, was used as received. The molecular structures of indicators are shown in Figure 1.

Two grams of PVA power was dissolved in $50 \mathrm{ml}$ of de-ionized distilled water<smiles>CN(C)c1ccc(C(=C2C=CC(=[N+](C)C)C=C2)c2ccc(N(C)C)cc2)cc1</smiles><smiles>CN(C)c1ccc(/N=N/c2ccccc2C(=O)O)cc1</smiles><smiles>CN(C)c1ccc2nc3ccc(=[N+](C)C)cc-3sc2c1</smiles><smiles>CN(C)c1ccc(/N=N/c2ccc(S(=O)(=O)[O-])cc2)cc1</smiles>

(d)

Figure 1. The molecular structures of crystal violet (a), methyl red (b), methylene blue (c) and methyl orange (d). 
by heating up to $60^{\circ} \mathrm{C}$ and stirred for homogeneous solution (magnetic heater). PVA solution changed transpicuous color was added $1 \mathrm{~mL}$ crystal violet $2 \times 10^{-3}$ $\mathrm{M}$ and further stirred for half an hour so as to obtain a colored PVA solution uniformly. Films of this solution were prepared by pouring it on a flat glass plate when temperature of solution was from $45^{\circ} \mathrm{C}$ to $50^{\circ} \mathrm{C}$. The dyed PVA films would dry naturally within 72 hours at room temperature. CV-PVA film was peeled off the glass plate and cut into thin films of $0.8 \mathrm{~cm} \times 4 \mathrm{~cm}$. Each sample was sealed into a dark plastic pouch and stored in desiccator at laboratory conditions.

The MR-PVA dyed films, the MB-PVA dyed films and the MO-PVA dyed films were prepared same the CV-PVA dyed films.

$\mathrm{Co}^{60} \gamma$-source from Hanoi Irradiation Center, Vietnam Atomic Energy Institute have $4.07 \times 10^{15} \mathrm{~Bq}$ radioactive activity. The samples were irradiated with the dose range $1-150 \mathrm{kGy}$ at temperature $23^{\circ} \mathrm{C}$. The UV-VIS 2450 spectrophotometer was used to measure the optical absorption spectra of the unirradiated films and irradiated films.

From the results of optical density values on the pre and post-irradiation films, we determined the gamma dose response curves and investigated the different color sensitivity of four film types with four different colors.

\section{Results and Discussion}

\subsection{Absorption Spectra}

The optical absorption spectra of unirradiated and irradiated films were measured in the wavelength range of $540-660 \mathrm{~nm}$ and maximum at $599 \mathrm{~nm}$ with CV-PVA, $400-600 \mathrm{~nm}$ and maximum at $520 \mathrm{~nm}$ with MR-PVA, $500-750 \mathrm{~nm}$ and maximum at $668 \mathrm{~nm}$ MB-PVA and $300-600 \mathrm{~nm}$ and maximum at $440 \mathrm{~nm}$ with MO-PVA as shown in the Figures 2-5. The colors for films of CV-PVA

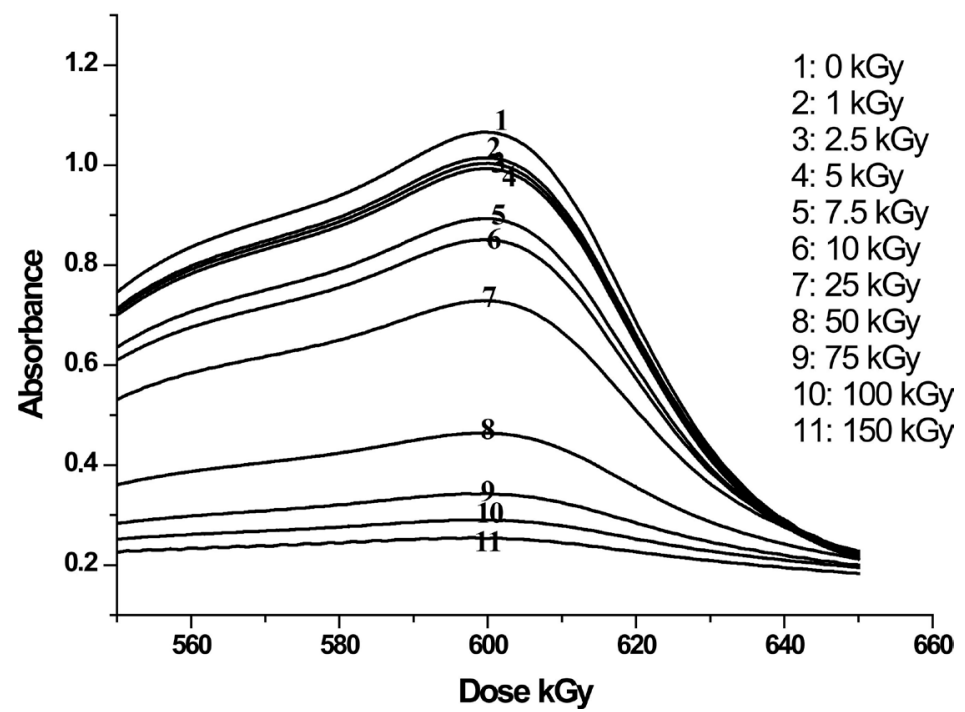

Figure 2. The absorption spectra of unirradiated and irradiated CV-PVA films measured at wavelength range $540-650 \mathrm{~nm}$ for difference doses. 


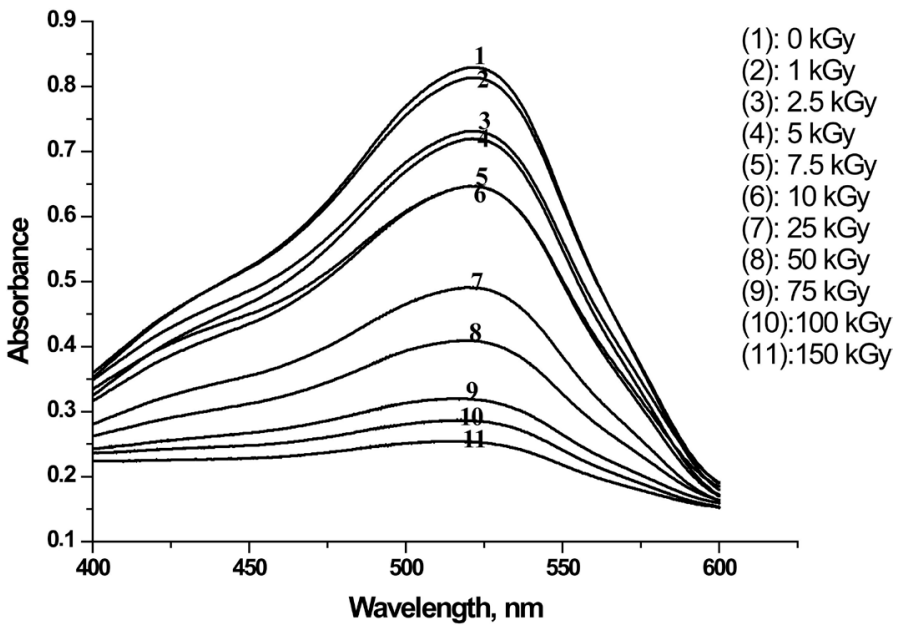

Figure 3. The absorption spectra of unirradiated and irradiated MR-PVA films measured at wavelength range $400-600 \mathrm{~nm}$ for difference doses.

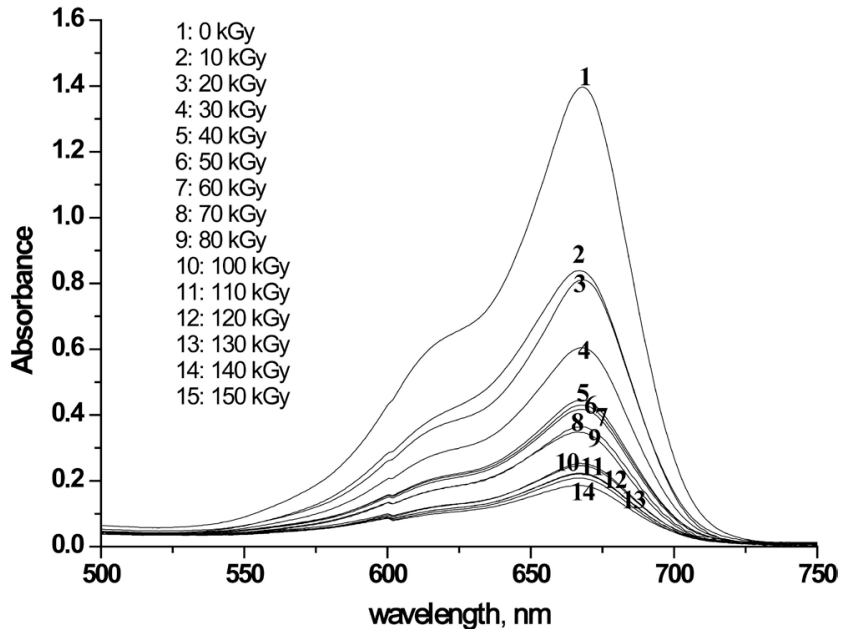

Figure 4. The absorption spectra of unirradiated and irradiated MB-PVA films measured at wavelength range $500-750 \mathrm{~nm}$ for difference doses.

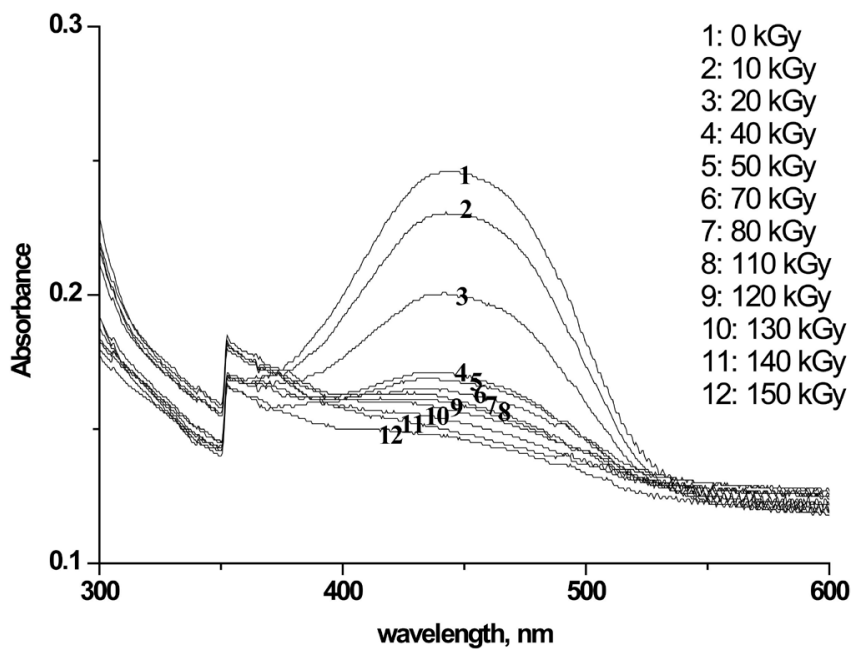

Figure 5. The absorption spectra of unirradiated and irradiated MO-PVA films measured at wavelength range $300-600 \mathrm{~nm}$ for difference doses. 
changed from dark purple to light purple, MR-PVA changed from dark pink to light pink, MB-PVA changed from dark blue to light blue and MO-PVA changed from yellow to light pink.

The amplitude of these absorption bands decreased gradually with the increase of dose of $\gamma$-ray without changing $\lambda_{\max }$. The change in optical density at $\lambda_{\max }$ per unit thickness increased when $\gamma$-ray dose increased.

\subsection{Response Curves}

The response curves have been built by characteristic functions of radioactive energy transfer from $\gamma$-source to material made dosimeters. The energy transfer process is mainly performed by $\delta$-electrons. They get enough energy and leave their orbits in the atom to become free electrons. According to the energy transfer model, the response curves of the dyed PVA films can be expressed as the saturated exponential function of the optical density values $n(D)$ as follows:

$$
n(D)=n_{s}\left[1-e^{-k D}\right]+n_{o} e^{-k D}
$$

where $D$ is dose; $n_{0}$ and $n_{s}$ are respectively number of the activated element at $D$ $=0$ and $D=\infty ; k$ is the total probability that one radiation sensitive element of the system will be activated per unit of time. In fact, $k$ consists of two components:

$$
k=p+q
$$

where $p$ is the probability that one sensitive element will be activated per unit of time; $q$ is the probability that one activated element experiences reactivation per unit of time [11] [12].

Optical densities of the dyed PVA films decreased when they irradiated gamma source with increasing dose. The absorbance reductions of films were fitted in formula (1) giving the response curves (as the dose characteristic function) which depicted in Figure 6 and Table 1.

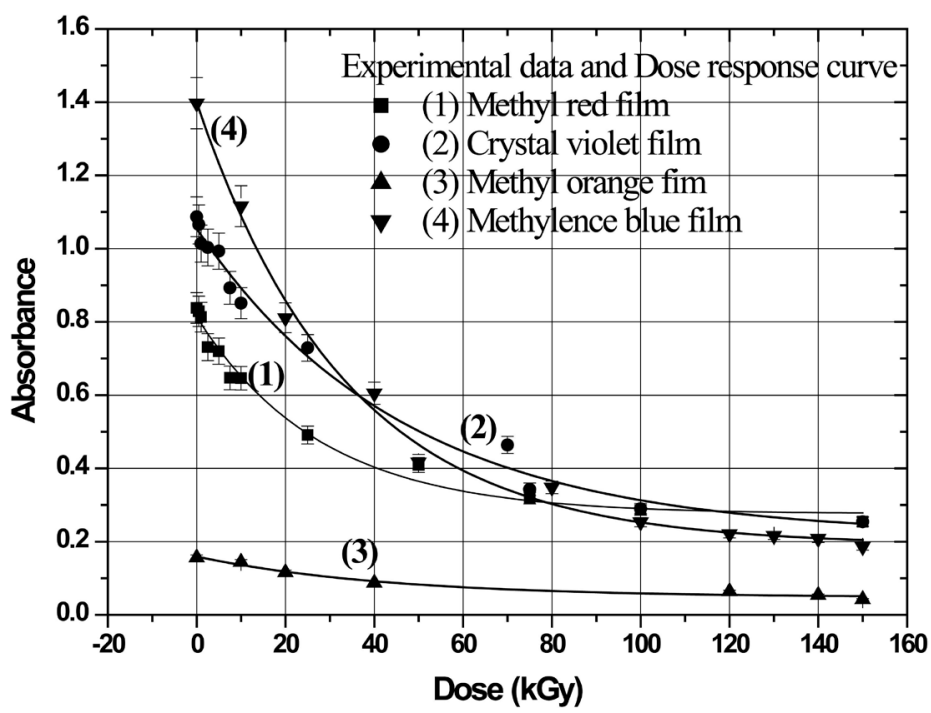

Figure 6. The response curves of the dyed PVA films. 
Table 1. The coefficients of the gamma dose response curves.

\begin{tabular}{cccccc}
\hline Dyed film & $\boldsymbol{n}_{\boldsymbol{o}}$ & $\boldsymbol{n}_{\boldsymbol{s}}$ & $\boldsymbol{n}_{o} / \boldsymbol{n}_{\boldsymbol{s}}$ & $\boldsymbol{k}$ & $\boldsymbol{R}^{2}$ \\
\hline Methyl red & $0.814 \pm 0.011$ & $0.276 \pm 0.021$ & $2.955 \pm 0.227$ & $0.036 \pm 0.005$ & 0.98664 \\
Crystal violet & $1.052 \pm 0.014$ & $0.214 \pm 0.030$ & $4.909 \pm 0.689$ & $0.023 \pm 0.005$ & 0.99426 \\
Methyl orange & $0.159 \pm 0.007$ & $0.051 \pm 0.006$ & $3.100 \pm 0.404$ & $0.024 \pm 0.005$ & 0.96574 \\
Melthylene blue & $1.399 \pm 0.031$ & $0.190 \pm 0.020$ & $7.352 \pm 0.788$ & $0.030 \pm 0.002$ & 0.99435 \\
\hline
\end{tabular}

Thus, the gamma dose response curves of the dyed PVA films determined by saturated exponential function of the energy transfer model are perfectly consistent with the high correlation coefficient between theory and experiment.

\subsection{Sensitivity of the Dyed PVA Films}

To assess the color variability of the dyed PVA films which were irradiated by the gamma source, we determined the color sensitivity of a dosimeter by the formula:

$$
s=\frac{n_{0}}{n_{s}}
$$

where $n_{0}$ and $n_{s}$ are respectively number of the activated element at $D=0$ and $D$ $=\infty$. From expression (3) it is clear that $s$ value (the color sensitivity) is big, the discolorment of the film is big. The sensitivities of different dyed films were shown in Table 1. These results showed that The MB-PVA dyed films were the best dosimeters, while MR-PVA dyed films were the bad dosimeters.

\section{Conclusion}

Study on the optical density change of the dyed PVA films at pre and post irradiation by $\mathrm{Cs}^{137} \gamma$-source in dose range of $1-150 \mathrm{kGy}$ shows that the $\gamma$-ray absorptions of these films were described by saturated exponential function of the energy transfer model. They are appropriate to make dosimeters for routine irradiation processes. The sensitivity results indicate that the MB-PVA dyed films are the best dosimeter.

\section{References}

[1] Lavrentovich, Ya.I., Levon, A.I., Mel'nikova, G.N. and Kabakchi, A.M. (1965) Gamma and Neutron Dosimetry in Nuclear Reactors by Means of Colored Polyvinyl Alcohol Films. Soviet Atomic Energy, 19, 1189-1192. https://doi.org/10.1007/BF01127583

[2] Chapiro, A. (1962) Radiation Chemistry of Polymeric Systems. Interscience, London.

[3] Rosenberg, Y., Siegmann, A., Narkis, M. and Shkolnik, S. (1992) Low Dose $\gamma$-Irradiation of Some Fluoropolymers: Effect of Polymer Chemical Structure. Journal of Applied Polymer Science, 45, 783-795. https://doi.org/10.1002/app.1992.070450504

[4] Ichikawa, T. and Yoshida, H. (1990) Mechanism of Radiation-Induced Degradation 
of Poly(Methyl Methacrylate) as Studied by ESR and Electron Spin Echo Methods. Journal of Polymer Science Part A: Polymer Chemistry, 28, 1185-1196. https://doi.org/10.1002/pola.1990.080280519

[5] Muzeoldi, P. and Arnold, G. (1987) Ion Beam Modification of Insulators. Elsevier, Amsterdam.

[6] El-Sawy, N.M., El-Arnaouty, M.B. and Abdel Ghaffar, A.M. (2010) $\gamma$-Irradiation Effect on the Non-Cross-Linked and Cross-Linked Polyvinyl Alcohol Films. Journal Polymer-Plastics Technology and Engineering, 49, 169-177. https://doi.org/10.1080/03602550903284248

[7] Ebraheem, S. and El-Kelany, M. (2013) Dosimeter Film Based on Ethyl Violet-Bromophenol Blue Dyed Poly(Vinyl Alcohol). Journal of Polymer Chemistry, 3, 1-5. https://doi.org/10.4236/ojpchem.2013.31001

[8] Bhat, N.V., Nate, M.M., Bhat, R.M. and Bhat, B.C. (2007) Effect of $\gamma$-Radiation on Polyvinyl Alcohol Films Doped with Some Dyes and Their Use in Dosimetric Studies. Indian Journal of Pure \& Applied Physics, 45, 545-548.

[9] Akhtar, S., Hussain, T., Shahzad, A. and Qamar-ul-Islam (2013) The Feasibility of Reactive Dye in PVA Films as High Dosimeter. Journal of Basic \& Applied Sciences, 9, 420-423.

[10] Akhtar, S., Hussain, T., Shahzad, A. and Qamar-ul-Islam (2013) Radiation Induced Decoloration of Reactive Dye in PVA Films for Film Dosimetry. Journal of Basic \& Applied Sciences, 9, 416-419.

[11] Nghiep, T.D. and Kojima, T. (1996) An Energy-Transfer Model for Radiation Dosimetry. Communications in Physics, 6, 5-12.

[12] Nghiep, T.D. (2002) Radiation Safety Book. Science and Technology Publishing House, Vietnam. 